\title{
Metallic Nanoparticles Embedded in a Dielectric Matrix: Growth Mechanisms and Percolation
}

\author{
M. García del Muro, ${ }^{1}$ Z. Konstantinovic, ${ }^{1}$ M. Varela, ${ }^{2}$ X. Batlle, ${ }^{1}$ and A. Labarta ${ }^{1}$ \\ ${ }^{1}$ Departament de Física Fonamental i Institut de Nanociència i Nanotecnologia, Universitat de Barcelona, \\ Martí i Franquès 1, 08028 Barcelona, Spain \\ ${ }^{2}$ Departament de Física Aplicada i Òptica i Institut de Nanociència i Nanotecnologia, Universitat de Barcelona, \\ Martí i Franquès 1, 08028 Barcelona, Spain \\ Correspondence should be addressed to M. García del Muro, montse@ffn.ub.es
}

Received 1 October 2007; Accepted 26 December 2007

Recommended by Ping Xiao

\begin{abstract}
We present a study of the preparation and structural characterization of granular $\mathrm{Ag}-\mathrm{ZrO} \mathrm{O}_{2}, \mathrm{Co}-\mathrm{ZrO}_{2}$, and $\mathrm{Au}-\mathrm{ZrO} \mathrm{H}_{2}$ thin films grown by pulsed laser deposition (PLD) in a wide range of volume fraction $x$ of metal $\left(0.08<x_{\mathrm{Ag}}<0.28,0.06<x_{\mathrm{Co}}<0.40\right.$, and $\left.0.08<x_{\mathrm{Au}}<0.55\right)$. High-resolution transmission electron microscopy (HRTEM) showed regular distribution of spherical Au, Co, and Au nanoparticles having very sharp interfaces with the amorphous matrix. The structural results are compared aiming to stress the effect of the actual microstructure on the percolation threshold. Two different mechanisms of particle growing as a function of the metal content are evidenced: nucleation and particle coalescence, with their relative significance depending strongly on the type of metal, giving rise to very different values of the percolation threshold $\left(x_{\mathrm{c}}(\mathrm{Ag}) \sim 0.28, x_{\mathrm{c}}(\mathrm{Co}) \sim 0.35\right.$, and $\left.x_{\mathrm{c}}(\mathrm{Au}) \sim 0.55\right)$.
\end{abstract}

Copyright (c) 2008 M. García del Muro et al. This is an open access article distributed under the Creative Commons Attribution License, which permits unrestricted use, distribution, and reproduction in any medium, provided the original work is properly cited.

\section{INTRODUCTION}

The latest great advances in fine particle systems field have been promoted by the development of new measuring techniques and refinement of synthesis methods allowing the preparation of particles at the nanometric scale with promising technological applications in many different fields. In particular, granular films, in which a distribution of ultrafine metallic particles is embedded in a dielectrix matrix, comprise a very active research topic. From a fundamental point of view, these composite systems show a variety of behaviors related to percolation processes that the standard percolation theories have not satisfactorily explained yet [1-3]. From technological aspect, spherical particles of noble metals homogeneously dispersed in dielectric matrix exhibit promising optical applications [4-6], associated with its large third-order nonlinear susceptibility [7-9] and ultrafast response [10] when approaching percolation. When the metal is magnetic, granular magnetic solids are excellent materials to study basic properties, such as finite-size interaction and surface effects, and enhanced and tailored properties [11]. From the technological point of view, their magnetic and magnetotransport properties also suggest attractive applications, including high coercive films for information storage $[12,13]$, high-permeability high-resistivity films for shielding and bit writing at high frequencies [14], and giant magnetoresistance for read heads and magnetic sensors [15].

In this paper, we present the preparation and structural characterization by HRTEM of granular Ag- $\mathrm{ZrO}_{2}, \mathrm{Co}-$ $\mathrm{ZrO}_{2}$, and $\mathrm{Au}-\mathrm{ZrO}_{2}$ thin films grown by PLD from a single composite target within a wide range of volume fraction $x$ of metal, from the dielectric regime until percolation $\left(0.08<x_{\mathrm{Ag}}<0.28,0.06<x_{\mathrm{Co}}<0.40\right.$, and $\left.0.08<x_{\mathrm{Au}}<0.55\right)$. Statistical analysis of TEM images provides us with the mean size and width of the size distribution as a function of metal concentration. In particular, we observe that for the three prepared metals, the mean size of the particles increases in a very different way with the metal content. The role played by the two identified growing mechanisms (coalescence and nucleation) is shown to be very different in these three systems, and so leading to different percolation threshold.

\section{EXPERIMENTAL}

$\mathrm{Ag}-\mathrm{ZrO}_{2}, \mathrm{Co}-\mathrm{ZrO}{ }_{2}$, and $\mathrm{Au}-\mathrm{ZrO}_{2}$ granular films were grown by $\mathrm{KrF}$ laser ablation (wavelength of $248 \mathrm{~nm}$, pulse duration 


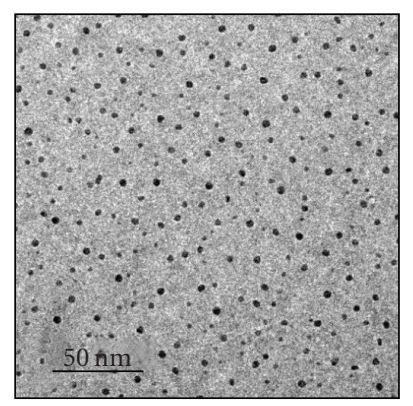

(a)

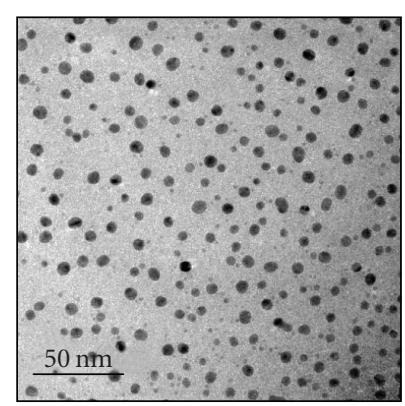

(b)

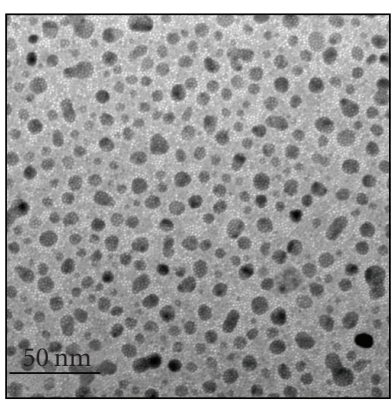

(c)

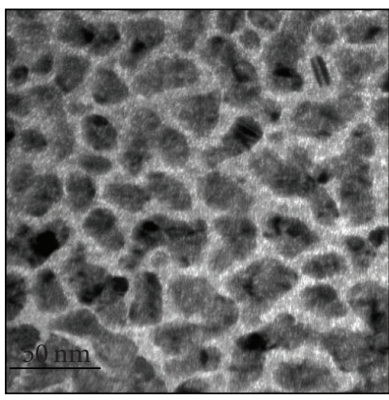

(d)

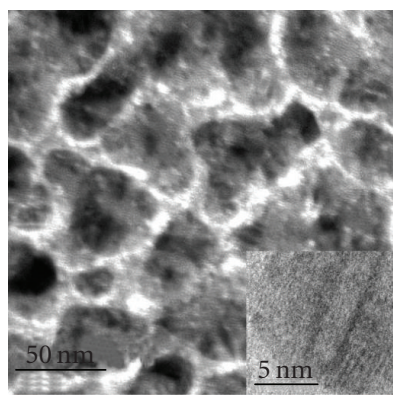

(e)

Figure 1: Bright field TEM images of Ag- $\mathrm{ZrO}_{2}$ films with (a) $x=0.08$, (b) $x=0.18$, (c) $x=0.23$, (d) $x=0.26$, and (e) $x=0.28$. The scale length is indicated in each image. The inset in Figure 1(e) shows lattice fringes inside an Ag particle.

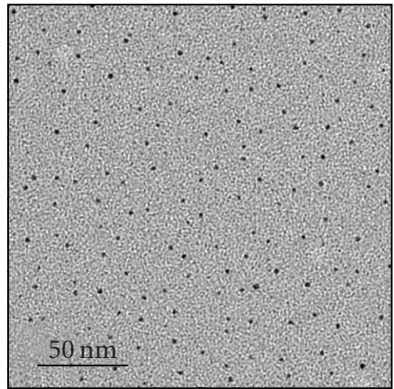

(a)

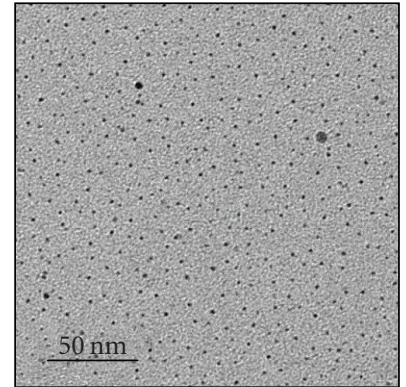

(b)

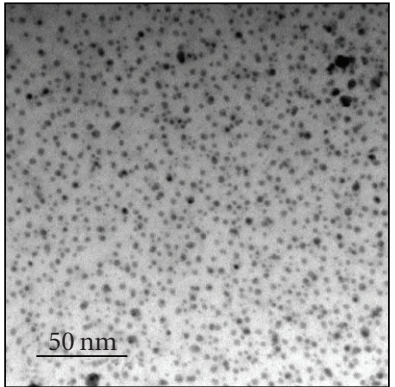

(c)

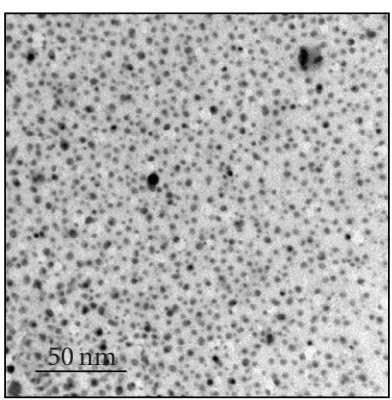

(d)

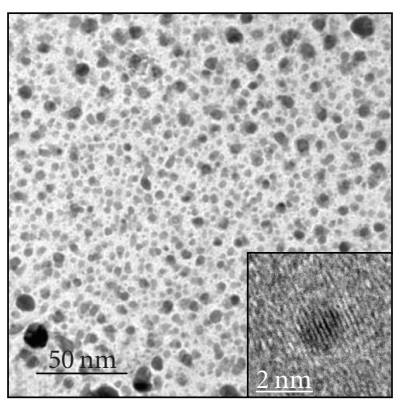

(e)

Figure 2: Bright field TEM images of Co-ZrO 2 films with (a) $x=0.06$, (b) $x=0.12$, (c) $x=0.25$, (d) $x=0.30$, and (e) $x=0.35$. The inset in Figure 2(e) shows lattice fringes inside a Co particle. 


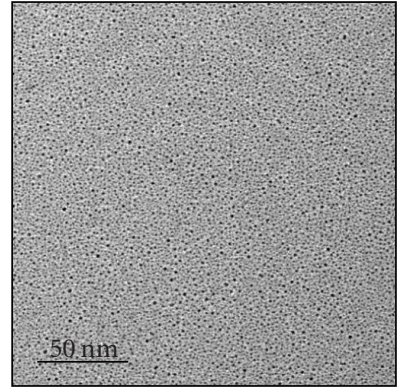

(a)

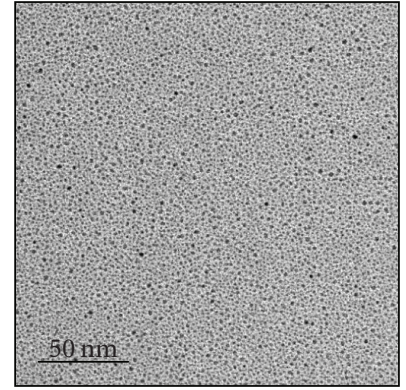

(b)

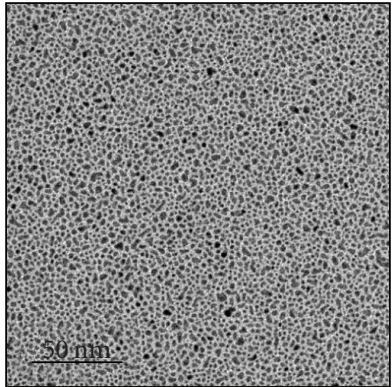

(c)

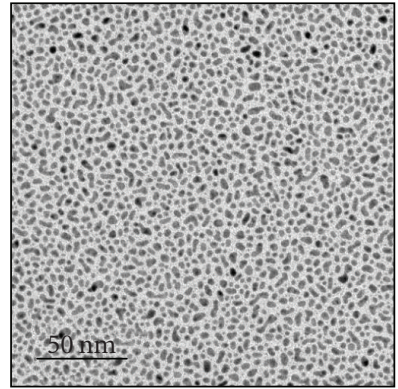

(d)

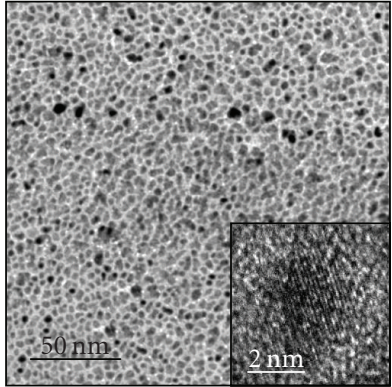

(e)

Figure 3: Bright field TEM images of Au-ZrO 2 films with (a) $x=0.08$, (b) $x=0.23$, (c) $x=0.41$, (d) $x=0.51$, and (e) $x=0.55$. The inset in Figure 3(e) shows lattice fringes inside an Au particle.

of $\tau=34 \mathrm{~ns})$. The samples were deposited at room temperature in a vacuum chamber with rotating composite targets made of sectors of $\mathrm{ZrO}_{2}$ and metal (silver, cobalt, or gold). Several surface ratios of target components led to obtainning samples with different volume fractions $x$ of $\mathrm{Ag} / \mathrm{Co} / \mathrm{Au}$, ranging from metallic to dielectric regimes. The distance between target and substrate was fixed to $35 \mathrm{~mm}$. The laser fluency typically used was about $2 \mathrm{~J} / \mathrm{cm}^{2}$. Zirconia was stabilized with $7 \mathrm{~mol} . \% \mathrm{Y}_{2} \mathrm{O}_{3}$, which provides the matrix with very good properties, such as good oxidation resistance, thermal expansion coefficient matching that of metal alloys, and very high fracture toughness values. It has been observed that $\mathrm{ZrO}_{2}$ matrix gives rise to sharper interfaces between the amorphous matrix and nanoparticles [16]. Besides, the high oxygen affinity of $\mathrm{ZrO}_{2}$ prevents oxidation of the metallic nanoparticles.

Sample composition was determined by microprobe analyses. The size distribution of metal nanoparticles was determined from TEM. The substrates for TEM experiments were membrane windows of silicon nitride, which enabled direct observation of as-deposited samples.

\section{RESULTS AND DISCUSION}

The analysis of TEM images allowed us to obtain the particles size distribution for each metal concentration. TEM images provide direct observation of the nanoparticles even for very low metal contents. Typical TEM images are shown in Figure 1 for $\mathrm{Ag}-\mathrm{ZrO}_{2}$, in Figure 2 for $\mathrm{Co}-\mathrm{ZrO}_{2}$, and in Figure 3 for $\mathrm{Au}-\mathrm{ZrO}_{2}$. The dark regions correspond to the
$\mathrm{Ag}, \mathrm{Co}$, and $\mathrm{Au}$ particles and the light regions to the amorphous $\mathrm{ZrO}_{2}$ matrix. The particles are seen to have clearly defined interfaces with the matrix.

The lattice fringes observed in the metal grains correspond to $\mathrm{Ag} / \mathrm{Co} / \mathrm{Au}$ atomic planes indicating good crystallinity even for very low metal content (see insets to Figures 1-3). Lattice fringes are not present in the $\mathrm{ZrO}_{2}$ matrix, confirming its amorphous nature.

The particles have spherical shape for $x_{\mathrm{Ag}}<0.18$, $x_{\mathrm{Co}}<0.25$, and $x_{\mathrm{Au}}<0.41$, (see Figures 1(a) and 1(b), 2(a)$2(\mathrm{c})$, and $3(\mathrm{a})$ and $3(\mathrm{~b}))$. For $x_{\mathrm{Ag}}>0.18, x_{\mathrm{Co}}>0.25$, and $x_{\mathrm{Au}}>0.41$, the neighboring particles start to coalesce, giving rise to larger particles not always with spherical shape (see elongated particles in Figures 1(b)-1(d), 2(d), and 3(c) and $3(d))$. Increasing the metal content, the particles form big aggregates (see Figures 1(e), 2(e), and 3(e)), indicating rapid approaching to the percolation threshold, above which metal forms a continuum.

The distributions of particle size are well described by a log-normal function:

$$
f(D)=\frac{1}{\sqrt{2 \pi} \sigma D} \exp \left[-\frac{\ln ^{2}\left(D / D_{0}\right)}{2 \sigma^{2}}\right],
$$

where the fitting parameters $D_{0}$ and $\sigma$ are the most probable particle size and the width of the distribution, respectively, (see Table 1). At low Ag content, the particle size distribution is centered between 1 and $2 \mathrm{~nm}$ (see Figure 1(a)). Increasing the Ag content, the size distribution shifts towards larger sizes, due to coalescence of smaller particles into the big ones, 
TABle 1: Particle size distribution parameters obtained from TEM data as a function of the metal volume concentration $(x): D_{0}$ (most probable diameter), $D_{M}$ (average particle diameter, $D_{M}=$ $D_{0} \exp \left(\sigma^{2} / 2\right)$ ), and $\sigma$ (with of the distribution).

\begin{tabular}{cccc}
\hline$x_{\mathrm{Ag}}$ & $D_{0}(\mathrm{~nm})$ & $D_{M}$ & $\sigma$ \\
\hline 0.08 & 1.7 & 1.8 & 0.40 \\
0.18 & 11 & 11.2 & 0.20 \\
0.23 & 17 & 17.4 & 0.22 \\
0.26 & 39 & 39.9 & 0.21 \\
0.28 & 220 & 249.3 & 0.50 \\
\hline$x_{\mathrm{Co}}$ & $D_{0}(\mathrm{~nm})$ & $D_{M}$ & $\sigma$ \\
\hline 0.06 & 2.0 & 2.0 & 0.20 \\
0.12 & 2.7 & 2.8 & 0.25 \\
0.25 & 7 & 7.4 & 0.35 \\
0.30 & 10.5 & 11.0 & 0.30 \\
0.35 & 14 & 15.5 & 0.45 \\
\hline$x_{\mathrm{Au}}$ & $D_{0}(\mathrm{~nm})$ & $D_{M}$ & $\sigma$ \\
\hline 0.08 & 1.2 & 1.3 & 0.45 \\
0.23 & 2 & 2.2 & 0.40 \\
0.41 & 3 & 3.3 & 0.45 \\
0.51 & 5.9 & 6.1 & 0.25 \\
0.55 & 9.5 & 10 & 0.32 \\
\hline
\end{tabular}

which produces a net narrowing effect on the particle size distribution ( $\sigma$ goes from 0.4 to 0.2 ). About $x_{\mathrm{Ag}}=0.28$, the size distribution broadens abruptly $(\sigma=0.5)$ because of massive coalescence of the nanoparticles taking place at percolation.

A quite different evolution of the microstructure is observed for $\mathrm{Au}-\mathrm{ZrO}_{2}$ as the $\mathrm{Au}$ content is increased. At low Au content, the width of the particle size distribution is similar to that observed for silver with $x_{\mathrm{Ag}}=0.08$. Nevertheless, in this case, a very smooth shift of the size distribution towards larger sizes is observed even for Au contents as high as $x_{\mathrm{Au}}=0.41$ (see Table 1 ), suggesting that in a wide range of concentrations Au particles tend to be coated by the matrix, which minimizes particle coalescence and maintains the width of the size distribution almost constant. The onset of coalescence processes takes place about $x_{\mathrm{Au}}>0.41$, giving rise to a similar narrowing of the size distribution (from $\sigma=0.45$ to $\sigma=0.25$ ) as it is also observed in $\mathrm{Ag}-\mathrm{ZrO}_{2}$, but in this case occurring at metal contents very close to percolation. Finally, at $x_{\mathrm{Au}} \sim 0.55$ massive coalescence of the nanoparticles arising from percolative processes takes place, which produces a broadening of the size distribution, as it is also observed for $\mathrm{Ag}-\mathrm{ZrO}_{2}$. In the case of the $\mathrm{Co}-\mathrm{ZrO}_{2}$ system, the evolution of the microstructure is closer to Au than to Ag. The coalescence is observed to start about $x_{\mathrm{Co}}>0.25$ (see Figure $2(\mathrm{~d})$ ), where the width of the size distribution becomes narrower (see Table 1), and a final increase in $\sigma$ is observed for $x_{\mathrm{Co}}=0.35$, anouncing percolation.

Average particle size for silver, cobalt, and gold increases with metal concentration, but following very different behaviors. With increasing Au content, mean particle size slightly increases, since in this case and below about $x_{\mathrm{Au}}=0.04$,

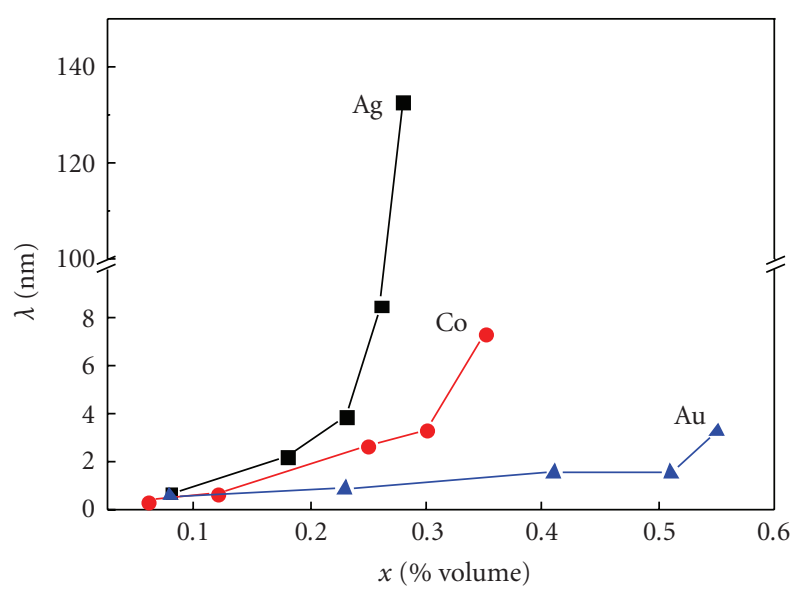

FIgURE 4: Standard deviation of the size distribution versus metal content.

particles grow essentially by condensation of the gold atoms available in the neighborhood of each nucleating seed, according to TEM images (see Figures 3(a) and 3(b)). However, for $\mathrm{Ag}-\mathrm{ZrO}_{2}$, the mean particle size increases abruptly with $x_{\mathrm{Ag}}$ because particle growth is arising from nucleation and further coalescence of neighboring particles even at low metal contents. The $\mathrm{Co}-\mathrm{ZrO}_{2}$ is an intermediate case between the extreme behaviors of $\mathrm{Au}-\mathrm{ZrO}_{2}$ and $\mathrm{Ag}-\mathrm{ZrO}$.

The role played by the two different mechanisms of particle growing observed in $\mathrm{Ag}-\mathrm{ZrO}_{2}, \mathrm{Co}-\mathrm{ZrO}_{2}$, and $\mathrm{Au}-\mathrm{ZrO}_{2}$ granular films gives rise to very different values of the percolation threshold in these granular materials. The approach to percolation with the metal content can be better evidenced by the abrupt increase of the standard deviation of the size distribution, defined as $\lambda=D_{M}\left[\exp \left(\sigma^{2}\right)-1\right]^{1 / 2}[17]$. Figure 4 shows the variation of $\lambda(x)$. The metal contents, at which massive particle coalescence preceding percolation takes place, correspond to the range of the $\lambda(x)$ curves where a significant departure from linear behavior is observed. For $\mathrm{Ag}-\mathrm{ZrO}_{2}$, percolation threshold deduced from Figure 4 and according to TEM images $\left(x_{\mathrm{c}}(\mathrm{Ag}) \sim 0.28\right)$ is very close to the theoretical prediction for the model of random percolation of hard spheres [18]. In contrast, particle coalescence in Co$\mathrm{ZrO}_{2}$ and $\mathrm{Au}-\mathrm{ZrO}_{2}$ is inhibited by the better efficiency of the matrix to coat the particles with respect to silver ones, which retards the occurrence of percolating processes, shifting the critical value of the metal content to $x_{\mathrm{c}}(\mathrm{Co}) \sim 0.35$ and $x_{\mathrm{c}}(\mathrm{Au}) \sim 0.55$.

\section{CONCLUSIONS}

We have shown that pulsed laser deposition is an appropriate technique to prepare silver, cobalt, and gold nanoparticles embedded in $\mathrm{ZrO}_{2}$ matrix, in a wide range of volume concentration $\left(0.08<x_{\mathrm{Ag}}<0.28,0.06<x_{\mathrm{Co}}<0.40\right.$, and $\left.0.08<x_{\mathrm{Au}}<0.55\right)$. Sharp interfaces between rounded crystalline particles and amorphous matrix are observed in the as-prepared samples, without needing ulterior thermal treatment. The mean nanoparticle diameter increases with metal 
volume concentration, but through different mechanisms depending on the metal element. Silver nanoparticles are obtained in a wider range of diameters $(1-200 \mathrm{~nm})$ than that corresponding to cobalt $(2-15 \mathrm{~nm})$ and gold ones $(1-10 \mathrm{~nm})$ which were observed obtained under the same preparation conditions. Distinct microstructures are shown to be the consequence of the relative contribution of the two particlegrowing mechanisms: nucleation and particle coalescence. Consequently, the percolation thresholds are very different in these three systems, $\left(x_{\mathrm{c}}(\mathrm{Ag}) \sim 0.28, x_{\mathrm{c}}(\mathrm{Co}) \sim 0.35\right.$, and $\left.x_{\mathrm{c}}(\mathrm{Au}) \sim 0.55\right)$.

\section{ACKNOWLEDGMENTS}

The authors would like to thank the staff of the scientific and technical facilities of the University of Barcelona. Financial support of the Spanish CICYT (MAT2006-03999) and Catalan DURSI (2005SGR00969) is recognized.

\section{REFERENCES}

[1] F. Brouers, J. P. Clerc, G. Giraud, J. M. Laugier, and Z. A. Randriamantany, "Dielectric and optical properties close to the percolation threshold. II," Physical Review B, vol. 47, no. 2, pp. 666-673, 1993.

[2] A. B. Pakhomov, X. Yan, and B. Zhao, "Giant Hall effect in percolating ferromagnetic granular metal-insulator films," Applied Physics Letters, vol. 67, pp. 3497-3499, 1995.

[3] X. X. Zhang, C. Wan, H. Liu, Z. Q. Li, P. Sheng, and J. J. Lin, "Giant Hall effect in nonmagnetic granular metal films," Physical Review Letters, vol. 86, no. 24, pp. 5562-5565, 2001.

[4] Y. Hamanaka, K. Fukuta, A. Nakamura, L. M. Liz-Marzán, and P. Mulvaney, "Enhancement of third-order nonlinear optical susceptibilities in silica-capped Au nanoparticle films with very high concentrations," Applied Physics Letters, vol. 84, no. 24, pp. 4938-4940, 2004.

[5] Q. Wang, S. Wang, W. Hang, and Q. Gong, "Optical resonant absorption and third-order nonlinearity of $(\mathrm{Au}, \mathrm{Ag})-\mathrm{TiO}_{2}$ granular composite films," Journal of Physics D, vol. 38, no. 3, pp. 389-391, 2005.

[6] M. Maaza, O. Nemraoui, C. Sella, A. C. Beye, and B. BaruchBarak, "Thermal induced tunability of surface plasmon resonance in $\mathrm{Au}-\mathrm{VO}_{2}$ nano-photonics," Optics Communications, vol. 254, no. 1-3, pp. 188-195, 2005.

[7] K. D. Cummings, J. C. Garland, and D. B. Tanner, "Optical properties of a small-particle composite," Physical Review B, vol. 30, no. 8, pp. 4170-4182, 1984.

[8] I. Tanahashi, Y. Manabe, T. Tohda, S. Sasaki, and A. Nakamura, "Optical nonlinearities of $\mathrm{Au} / \mathrm{SiO}_{2}$ composite thin films prepared by a sputtering method," Journal of Applied Physics, vol. 79, no. 3, pp. 1244-1249, 1996.

[9] A. K. Sharma, J. F. Muth, A. Kvit, J. Narayan, and R. M. Kolbas, "Optical and structural characteristics of gold nanocrystallites embedded in a dielectric matrix," in Proceedings of the Materials Research Society Symposium J, vol. 617, Boston, Mass, USA, November 2000, 2.7.1.

[10] A. Polman, E. Snoeks, G. N. van den Hoven, et al., "Ion beam synthesis of planar opto-electronic devices," Nuclear Instruments and Methods in Physics Research B, vol. 106, no. 1-4, pp. 393-399, 1995.
[11] X. Batlle and A. Labarta, "Finite-size effects in fine particles: magnetic and transport properties," Journal of Physics D, vol. 35, no. 6, pp. R15-R42, 2002.

[12] S. Stavroyiannis, I. Panagiotopoulos, D. Niarchos, J. A. Christodoulides, Y. Zhang, and G. C. Hadjipanayis, "New $\mathrm{CoPt} / \mathrm{Ag}$ films for high density recording media," Journal of Applied Physics, vol. 85, pp. 4304-4306, 1999.

[13] M. Yu, Y. Liu, A. Moser, D. Weller, and D. J. Sellmyer, "Nanocomposite CoPt:C films for extremely high-density recording," Applied Physics Letters, vol. 75, no. 25, pp. 39923994, 1999.

[14] T. Morikawa, M. Suzuki, and Y. Taga, "Soft magnetic properties of Co-Cr-O granular films," Journal of Applied Physics, vol. 83, pp. 6664-6666, 1998.

[15] S. Mitani, H. Fujimori, K. Takanashi, et al., "Tunnel-MR and spin electronics in metal-nonmetal granular systems," Journal of Magnetism and Magnetic Materials, vol. 198-199, pp. 179184, 1999.

[16] B. J. Hattink, A. Labarta, M. García del Muro, X. Batlle, F. Sánchez, and M. Varela, "Competing tunneling and capacitive paths in $\mathrm{Co}-\mathrm{ZrO}_{2}$ granular thin films," Physical Review B, vol. 67, no. 3, Article ID 033402, 4 pages, 2003.

[17] I. Hrianca, C. Caizer, and Z. Schlett, "Dynamic magnetic behavior of $\mathrm{Fe}_{3} \mathrm{O}_{4}$ colloidal nanoparticles," Journal of Applied Physics, vol. 92, no. 4, pp. 2125-2132, 2002.

[18] C. D. Lorenz and R. M. Ziff, "Precise determination of the critical percolation threshold for the three-dimensional 'Swiss cheese' model using a growth algorithm," Journal of Chemical Physics, vol. 114, no. 8, pp. 3659-3661, 2001. 

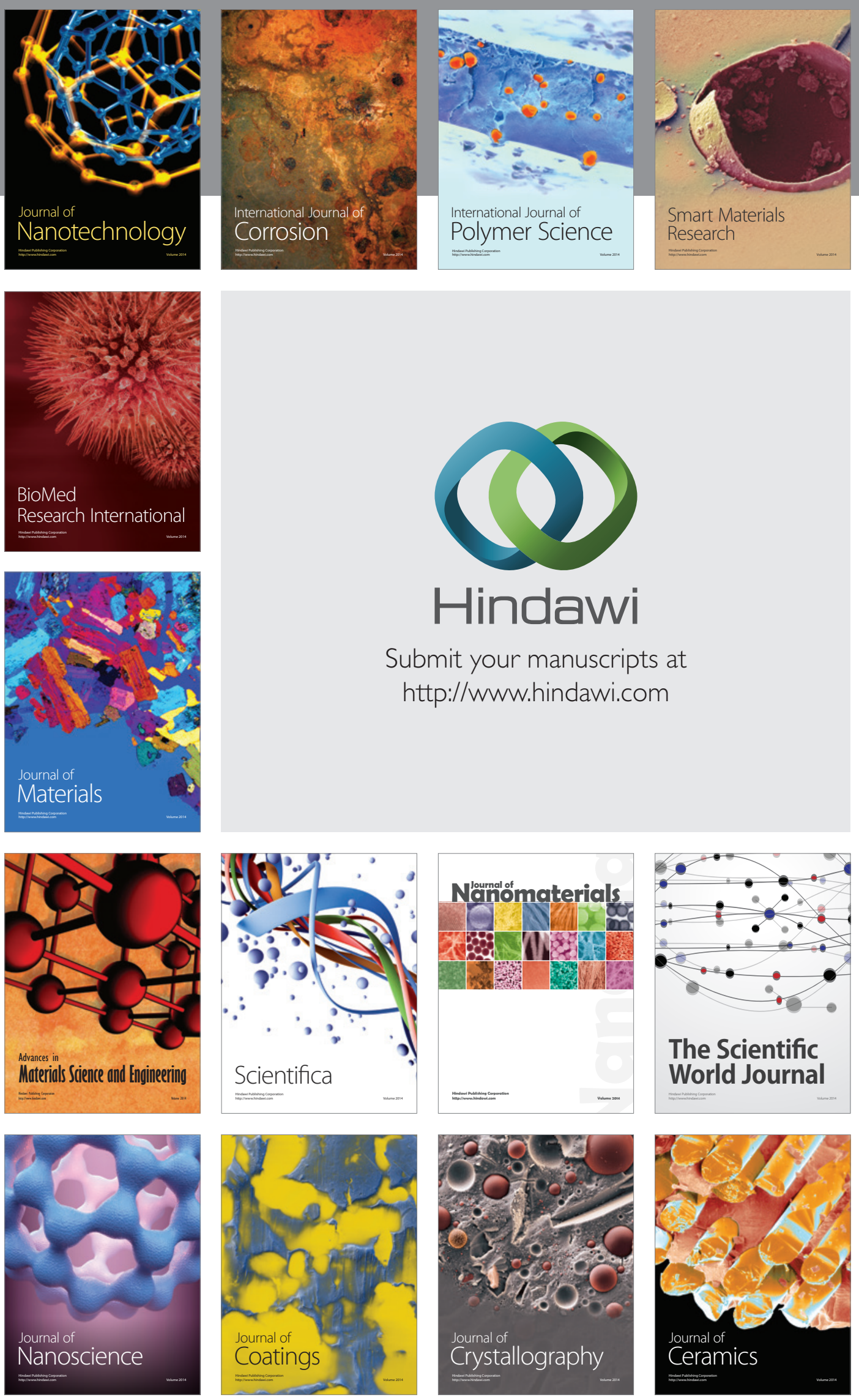

The Scientific World Journal

Submit your manuscripts at

http://www.hindawi.com

\section{World Journal}

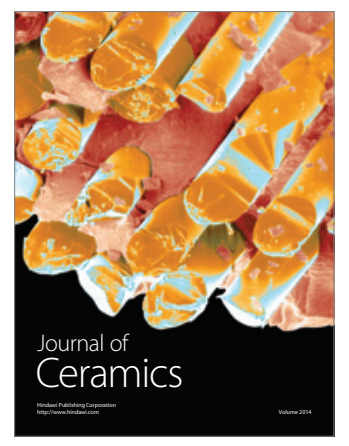

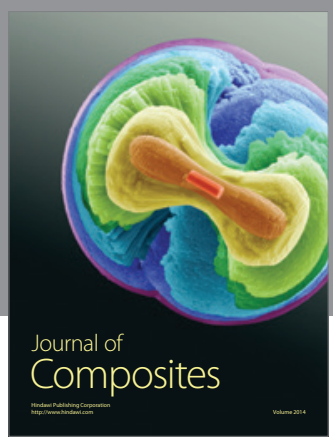
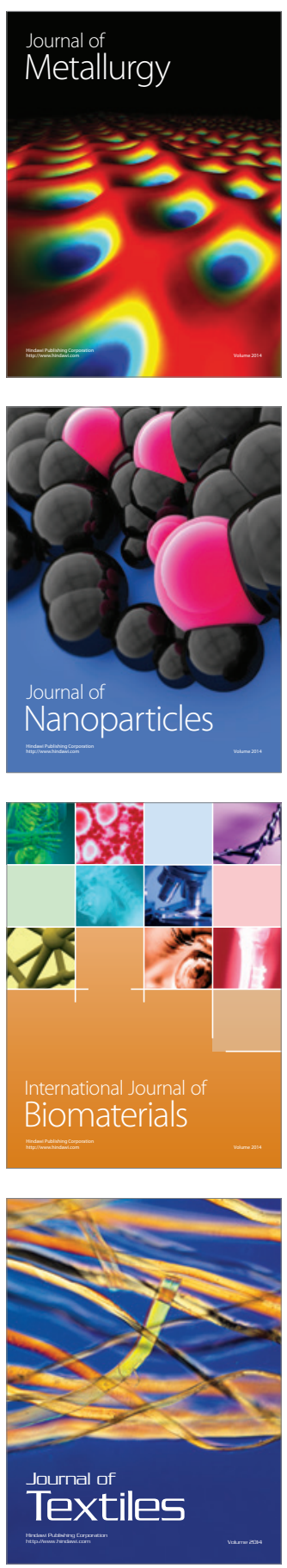